International Journal of Current Advanced Research

ISSN: O: 2319-6475, ISSN: P: 2319 - 6505, Impact Factor: SJIF: 5.995

Available Online at www.journalijcar.org

Volume 6; Issue 5; May 2017; Page No. 3747-3752

DOI: http://dx.doi.org/10.24327/ijcar.2017.3752.0361

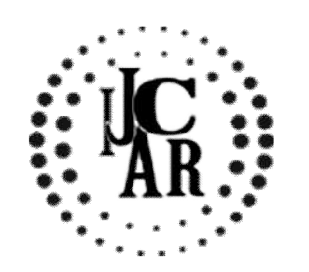

Research Article

\title{
THE EFFECT OF CHEMICAL FORMULA VISUALIZATION METHOD (CHEFOVIM) ON BALANCING SIMPLE INORGANIC CHEMICAL EQUATIONS
}

\author{
Uma Rajendran ${ }^{1}$ and M. Sadananthan ${ }^{2}$ \\ ${ }^{1}$ Department of Physical Sciences, Lakshmi College of Education \\ Gandhigram - 624302, Tamil Nadu \\ 2Department of Education, Manonmaniam Sundaranar \\ University, Tirunelveli, Tamil Nadu
}

A R T I C L E I N F O

\section{Article History:}

Received $1^{\text {st }}$ February, 2017

Received in revised form $12^{\text {th }}$ March, 2017

Accepted $15^{\text {th }}$ April, 2017

Published online $28^{\text {th }}$ May, 2017

\section{Key words:}

Chemical Formula, Balancing Simple Inorganic

\begin{abstract}
A B S T R A C T
A preliminary study revealed the difficulty of high school and higher secondary school students of Dindigul district, Tamil Nadu in balancing the inorganic chemical equations. Based on a computer program Chembalancer, the investigator attempted to design a novel method, CHEFOVIM (Chemical Formula Visualization Method) which doesn't require the use of a computer. The study was done employing the 'pre-test - post-test equivalent group experimental design'. A total of 120 students from IX standard from the rural schools in Dindigul district, Tamil Nadu formed the sample for the present study.. The reliability (0.78) and validity of the tool prepared were established. To find out the significant difference between the performance of students in the control and experimental groups ' $t$ ' test was done. The study revealed the effectiveness of the CHEFOVIM over the TM (Traditional Method) of teaching balancing of simple inorganic chemical equations.
\end{abstract}

Copyright $\odot 2017$ Uma Rajendra and M. Sadananthan. This is an open access article distributed under the Creative Commons Attribution License, which permits unrestricted use, distribution, and reproduction in any medium, provided the original work is properly cited.

\section{INTRODUCTION}

Chemistry plays an important role in science, industry and people's personal life. It is disheartening to note that education in and about the ideas in chemistry faces a range of challenges. The ideas of chemistry are found difficult to understand by many students. Indeed, what chemistry should be taught and how, to the students, is still very problematic. Thus, chemical education faces a number of important difficulties. Learning chemistry is highly demanding, perhaps more so than other school subjects. There is a need for better chemistry curricula, in place of those which are sometimes overloaded, vaguely structured and short of modern topics. Also in the education of chemistry teachers, as in their preservice teacher training courses, it is considered necessary to try and bridge the gap between the theories taught in these courses and the classroom reality experienced by prospective teachers.

\section{Chemistry education in schools}

\section{Any meaningful study of chemistry requires learners}

- to have grasped the notion of substance

*Corresponding author: Uma Rajendran

Department of Physical Sciences, Lakshmi College of Education Gandhigram - 624302, Tamil Nadu
- to appreciate that substances maintain their identity through a change of a state

- to recognize that during chemical changes

(a) the products are different substances to the reactants, yet

(b) there is a conservation of matter at a more fundamental level.There is a considerable literature which considers how learners respond to these challenges. Many studies have documented school students' conceptual difficulties (Johnstone, 2006) in the areas of

i) writing chemical formulae and equations

ii) balancing the chemical equations

iii) law of conservation of mass

iv) volumetric work involving molarities

v) Avogadro's number and the mole

vi) Chemical bonding

vii) Organic formulae

viii) Ion-electron equations

ix) Thermodynamics

x) Equilibrium

xi) Redox reactions

etc; At the secondary school level, chemistry has a negative image with many students as they experience difficulties in understanding the key concepts and rules. Many a student knows the chemical formula by heart, but does not understand 
its meaning (Howe and Jhonstone, 1971). Students' learning and understanding of chemistry is dependent on clear explanations of abstract chemical concepts. Explanatory tools such as models and chemical representations are central to the learning of chemistry. They are used in explaining scientific and chemical concepts to enhance students' learning and understanding and develop learners' mental models for chemical concepts (Hsin-Kai et al, 2000).

Students' conceptual understanding of chemical representations is thus a prominent area of research in chemistry education. For decades, researchers and chemistry educators have been discussing the three levels of representations in chemistry: macroscopic, microscopic, and symbolic levels (Jhonstone, 2006). Chemical representations at the macroscopic level refer to observable phenomena, such as the change of matter (Figure 1).

Macroscopic (observable phenomenon)

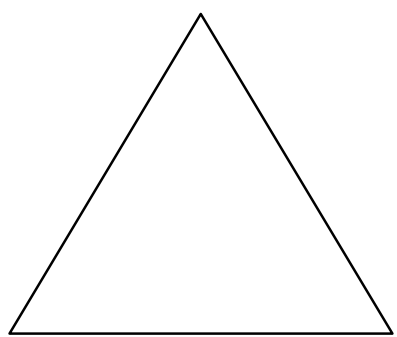

Submicroscopic
(atoms, molecules, ions
-nature, arrangement etc.,)

Symbolic

(symbols, formulae,graphs structures, equations)

Fig.1

The microscopic chemistry refers to the nature, the arrangement, and motion of molecules which are used to explain properties of compounds or natural phenomena. Chemistry at the symbolic level refers to the symbolic representations of atoms, molecules, and compounds, such as chemical symbols, formulae, and structures. Empirical studies (Ben-Zvi et al, 1988) have shown that learning microscopic and symbolic representations is especially difficult for students because these representations are invisible and abstract while students' understanding of chemistry relies heavily on sensory information. To help students understand chemistry at the three levels, researchers developed new approaches to teaching chemistry such as adapting teaching strategies based on the conceptual change model, using concrete models, and using technological tools (Gabel, 1998; Krajcik, 1991).

\section{Need for the present study}

Chemistry is a difficult subject to understand because it has many abstract concepts that are totally unfamiliar to students whose mental models are often in conflict with scientifically accepted explanations. When the investigator approached the chemistry teachers of the local schools (both at high and higher secondary level) in Dindigul district, Tamil Nadu to find out the areas in chemistry which were found to be difficult for their students, they expressed the following areas:
a) Writing the chemical formula for compounds
b) Balancing chemical equations
c) Naming of organic compounds
d) Isomerism

\section{e) Chemical bonding}

f) Thermodynamics etc.

The students also expressed the same. Learning to balance a chemical equation is very much essential for learning chemistry at the higher levels.

A chemical equation describes what happens in a chemical reaction. The equation identifies the reactants (the starting materials) and products (the resulting materials), the formulae of the participants, the phases of the participants (solid, liquid, gas) and the amount of each substance. Balancing a chemical reaction refers to establishing the mathematical relationship between the quantity of reactants and products. The balancing of a chemical reaction requires in students a thorough knowledge about -

- the concept of valency in writing the chemical formula of a compound

- the concept of variable valency for some elements, etc;

- the chemical formula of the substances that take part in the reaction,

- the Law of conservation of mass

- where to place the coefficients in the equation (as some students add the

- coefficients, the numbers as subscripts which will change the chemical formula

- and mathematical skill for writing and balancing the equations. Thus formal reasoning is required to balance even simple one-step chemical equations, while formal reasoning and a sufficiently large mental capacity (for information processing) are required to balance more complex, many step chemical equations. The students who are at the formal operational level easily learn how to balance the equations as they presumably have already acquired the necessary hypothetico-deductive reasoning pattern (Niaz and Lawson, 1985), whereas the students who are at the concrete operational level fail to learn to balance equations as they have failed to internalize the basic hypothetico-deductive reasoning pattern required to assimilate the instruction.

While empirical studies assert the value of using models and technological tools for learning balancing the chemical equations however, little is understood about how the students' visualization of the chemical formula of compounds taking part in a reaction help students to develop a conceptual understanding of balancing the chemical equations. Although there are many professional visualizing tools like ChemBalance Wizard which is a program ${ }^{1}$ that will rapidly balance chemical equations, it is not designed to predict the products of a reaction, but only balance the species (up to ten) input by the user. This is a 32-bit program designed to run under Window 95/NT. ChemBalancer is another online game ${ }^{2}$ that teaches how to balance chemical equations visually. With this program, the user types numbers in front of each molecule until the visual representation shows the same number of atoms on both sides of the equation. It works as a nice follow up to an in-class teaching on the subject. Smartboard activity-Balancing Equations is another software $^{3}$. All these tools need the use of computer by each student and there is no method designed to explore the 
visualizing capacity of the students to help them balance the equation by themselves at the high school level.

As Kozma and Russell (1997) point out, "understanding chemistryrelies on making sense of the invisible and the untouchable", explaining chemical reactions demands that a mental picture or model is developed to represent the submicroscopic particles in the substances being observed. Observations at the macroscopic level of changes in colour or volume of a reactant, or the evolution of a gas for example, reveal nothing about the sub-microscopic behaviour of the chemicals involved. Yet, explanations are nearly always at the sub-microscopic level, a level that cannot be observed - but is described and explained using symbols by which personal mental models are constructed.

Therefore, the purpose of this study is to design a novel methodology to develop the understanding of high school students to balance the chemical equations through visualizing and representing the chemical formula of chemicals involved in a reaction. This Chemical Formula Visualization Method (Chefovim) will help the students acquire a thorough understanding of what happens during a chemical reaction and will equip them to enter into formal operational stage with this thorough understanding. Also, most of the students even though they are in the formal operational stage (according to Piaget, above 11 years), they might not have been exposed to a thorough understanding of the concepts involved in balancing the chemical equations in the concrete operational stage visually and this might be an impediment to their learning in the future.

\section{Evolution of Chefovim}

From the preliminary survey conducted informally among the students and teachers at the high and higher secondary school levels, the investigator found that the students have difficulty in balancing the chemical equations. The investigator came across a computer program Chembalancer game that teaches how to balance chemical equations visually. With this program, the user types numbers (the co-efficient number for a molecule) in front of each molecule until the visual representation shows the same number of atoms on both sides of the equation. For example, the equation

$$
\mathrm{Cu}+\mathrm{O}_{2} \rightarrow \mathrm{Cu}_{2} \mathrm{O}
$$

has to be balanced by the student. For this, he types the coefficient number in front of the molecules to balance the equation. While he enters a number as coefficient before the chemical formula, student see the formula of the molecule the number of times the coefficient, on the computer screen. As he visualizes the individual elements in the molecule as in the form of their symbols (alphabet letters), they could easily type the coefficient of the molecules involved in the chemical reaction so that the equation is balanced. So the above equation is balanced as shown below.

Step 1: Computer - $\quad \mathrm{Cu}+\mathrm{O}_{2} \rightarrow \mathrm{Cu}_{2} \mathrm{O}$

Step 2: Student types the coefficient 2 for $\mathrm{Cu}, 1$ for $\mathrm{O}_{2}$ and 1 for $\mathrm{Cu}_{2} \mathrm{O}$

Step 3: Computer - $\begin{aligned} & 2 \mathrm{Cu}+1 \mathrm{O}_{2} \rightarrow 1 \mathrm{Cu}_{2} \mathrm{O} \\ & \mathrm{Cu}+\mathrm{O}-\mathrm{O} \rightarrow \mathrm{Cu}-\mathrm{O}-\mathrm{Cu}\end{aligned}$

Step 4: Student now easily visualizes the number of atoms involved in the reaction.
Step 5: Student add the coefficient appropriately before the chemical formula of molecules. ( 2 before $\mathrm{Cu}_{2} \mathrm{O}$ ).

Step 6: Computer - $\begin{array}{rl}2 \mathrm{Cu}+\mathrm{O}_{2} & \rightarrow 2 \mathrm{Cu}_{2} \mathrm{O} \\ \mathrm{Cu}+\mathrm{O}-\mathrm{O} \rightarrow \mathrm{Cu}-\mathrm{O}-\mathrm{Cu} \\ \mathrm{Cu} & \mathrm{Cu}-\mathrm{O}-\mathrm{Cu}\end{array}$

Step 7: Student visualizes the number of atoms on both the sides again and add the coefficient 4 before $\mathrm{Cu}$.

$$
\begin{aligned}
& 4 \mathrm{Cu}+\mathrm{O}_{2} \rightarrow 2 \mathrm{Cu}_{2} \mathrm{O} \\
& \text { Step 8: Computer }-\mathrm{Cu} \mathrm{Cu}+\mathrm{O}-\mathrm{O} \rightarrow \mathrm{Cu}-\mathrm{O}-\mathrm{Cu} \\
& \mathrm{Cu} \mathrm{Cu} \quad \mathrm{Cu}-\mathrm{O}-\mathrm{Cu}
\end{aligned}
$$

Now, the student visualizes the fully balanced equation. When this is done the computer gives the student the next equation for balancing. Thus the chemical equations are balanced using the Chembalancer programme. Here the student's job is to type only the coefficient number before the chemical formula of each compound/element. He tries various coefficient numbers for each molecule until he balances the number of atoms on both the sides of the equation.

This program made the investigator to improvise the Chefovim. As computers are not yet affordable to our school students, and as it was thought that this method could easily reach the student to understand the concepts involved in balancing the simple chemical equation, the Chembalancer program was modified in such a manner that the students themselves supply the expanded formula of the chemicals (instead of computer supplying them) involved in the chemical equation as represented by the alphabet letters, see the number of atoms involved in the reaction and balance the equation. For this, the students should be practised first in writing the expanded chemical formula, then visualize the number of each atom present on either side of the equation and add the number of times the expanded chemical formula of each molecule as required, for balancing the equation. Thus the Chemical Formula Visualization Method (CHEFOVIM) was evolved (for more reactions see Appendix).

\section{Objectives of the study}

The primary objective of the present study is to find out the effectiveness of Chemical Formula Visualization Method (CHEFOVIM) on balancing simple inorganic chemical equations by IX standard students.

\section{The following are the specific objectives of the present study:}

1. To develop and validate a tool to evaluate the achievement of students in balancing simple inorganic chemical equations

2. To find out the effectiveness of the CHEFOVIM by comparing the performance of the students who have undergone the CHEFOVIM method with those who have undergone the TM.

3. To find out the effect of sex on the achievement scores of the students in balancing the chemical equations

4. To find out the effect of medium of instruction on the achievement scores of the students in balancing the chemical equations

\section{Research hypotheses}

The following research hypotheses were framed for the study 
1. There is no significant difference between the achievement scores of control group and experimental group students in the pre-test.

2. There is no significant difference between the achievement scores of control group and experimental group students in the post-test.

3. There is no significant difference between the pre-test and post-test achievement scores of the control group students.

4. There is no significant difference between the pre-test and post-test achievement scores of the experimental group students.

5. There is no significant difference between the achievement scores of boys and girls of the control group in the pre -test as well as in the post test.

6. There is no significant difference between the achievement scores of boys and girls of the experimental group in the pre -test as well as in the post test.

7. There is no significant difference between the achievement scores of English medium and Tamil medium students of the control group in the pre-test as well as in the post-test.

8. There is no significant difference between the achievement scores of English medium and Tamil medium students of the experimental group in the pretest as well as in the post test.

\section{Sample of the study}

60 students (30 boys and 30 girls) of IX standard from Thambithottam Higher secondary school (TTHSS School) constituted the experimental group for whom the CHEFOVIM intervention programme was introduced. 60 students (30 boys and 30 girls) of IX standard from Devangar Boys' Higher secondary school (DBHSS) constituted the Control group for whom the balancing of inorganic chemical equation was taught by TM (Table 1). Both the groups were equated on the basis of sex, medium of instruction and their performance in the science test. The ' $t$ ' test revealed no significant difference between the two groups in their performance in the science test.

Table 1 The sample size

\begin{tabular}{cccccc}
\hline \multirow{2}{*}{ Group } & \multicolumn{2}{c}{ IX } & \multicolumn{2}{c}{ IX } & \multirow{2}{*}{ Total } \\
& English medium & Tamil medium & \\
\hline Control Group & 15 & 15 & 15 & 15 & 60 \\
Experimental Group & 15 & 15 & 15 & 15 & 60 \\
Total & 30 & 30 & 30 & 30 & 120 \\
\hline
\end{tabular}

\section{Variables of the study}

The independent variables involved in the present study are CHEFOVIM and TM and the dependent variable was the achievement of the students in balancing the chemical equations. The intervening variables were the medium of instruction and sex of the students.

\section{Design of the study}

The investigator employed 'Pretest - Post test Equivalent Groups Experimental Design'. A pre-test was conducted for both the groups. Then the balancing of chemical equations was taught to the control students by TM by their science/chemistry teacher and by CHEFOVIM to the experimental group by the investigator. Post-tests were conducted at the end of the treatment and the mean gain scores were compared and subjected to ' $t$ ' test to find out the significant difference between them at 0.05 level.

\section{Preparation and Validation of the test tool}

In the present study, the investigator prepared the test items with reference to the instructional objective that the students should balance the given simple chemical equations. At first 50 simple inorganic chemical equations from the high and higher secondary science/chemistry textbooks were selected. This was administered to 100 students of XI standard, who were randomly selected in two schools at Dindigul. The answer scripts corrected were arranged in the ascending order of scores. Item analysis was done and the difficulty index and discriminative index were found out for each item. The items having difficulty index value 40-65 and discrimination index above 0.4 were retained and the other items were eliminated. The final test tool consisted of 25 test items. A panel of experts handling the subject chemistry was asked to go through it. The agreement of the view of the experts was taken as the index of the content validity of the tool.

\section{Reliability of the tool}

The split-half method was adopted for establishing reliability of the tool. 50 students were randomly selected among the XI standard students of Government Adidravida School, Muruganpatti. The test was administered to these students. The Correlation coefficient between the two sets of scores was found to be 0.78 .

\section{Statistical techniques followed}

To find out the significant difference between the mean achievement scores of the control and experimental groups, ' $t$ ' test was used.

Table - 1 Comparison of pre-test mean scores of control group and experimental group

\begin{tabular}{cccccccc}
\hline Group & $\mathbf{N}$ & $\mathbf{X}$ & $\mathbf{S}$ & Df & t-stat & t-crit & Significance \\
\hline Control & 60 & 6.71 & 5.01 & & & & \\
& & & & 118 & 0.26 & 1.98 & NS* \\
Experimental & 60 & 6.9 & 4.53 & & & & \\
\hline \multirow{2}{*}{ No significant difference at 0.05 level. }
\end{tabular}

Table 2 Comparison of post-test mean scores of control group and experimental group

\begin{tabular}{cccccccc}
\hline Group & $\mathbf{N}$ & $\mathbf{X}$ & $\mathbf{s}$ & $\mathbf{D f}$ & t-sta1 & t-crit & Significance \\
\hline Control & 60 & 9.08 & 4.41 & & & & \\
& & & & 118 & 11.1 & 2.62 & $\mathrm{~S}^{*}$ \\
Experimental & 60 & 17.63 & 4.02 & & & &
\end{tabular}

* Significant difference at 0.01 level

Table 3 Comparison Of Pre-Test And Post-Test Mean Scores Of Control Group

\begin{tabular}{cccccccc}
\hline Test & N & $\mathbf{X}$ & S & Df & t-stat & t-crit & Significance \\
\hline & 60 & 6.71 & 5.01 & & & & \\
Pre-test & & & & 118 & 2.76 & 2.62 & S* \\
Post-test & 60 & 9.08 & 4.41 & & & & \\
\hline
\end{tabular}

*Significant difference at 0.01 level

Table 4 Comparison of pre-test and post-test mean scores of experimental group

\begin{tabular}{cccccccc}
\hline Test & $\mathbf{N}$ & $\mathbf{X}$ & $\mathbf{S}$ & Df & t-stat & t-crit & Significance \\
\hline Pre-test & 60 & 6.3 & 4.53 & & & & \\
& & & & 118 & 13.41 & 2.62 & $\mathrm{~S}^{*}$ \\
Post-test & 60 & 17.63 & 4.02 & & & &
\end{tabular}

* Significant difference at 0.01 level 


\section{Findings}

The findings of the present study derived from the data analysis are presented here.

1. There is no significant difference between the mean scores of the control group andexperimental group students in the pre-test.

2. There is significant difference between the mean scores of the control group and experimental group students in the post-test.

3. There is significant difference between the mean scores of the control group in the pretest and post-test.

4. There is significant difference between the mean scores of the experimental group in the pre-test and post-test.

5. There is no significant difference between the mean scores of boys and girls of the control group in the pre-test as well as in the post test.

6. There is no significant difference between the mean scores of boys and girls of the experimental group in the pre-test as well as in the post test.

7. There is no significant difference between the mean scores of IX standard English medium and Tamil medium students of the control group in the pre-test as well as in the post test.

8. There is no significant difference between the mean scores of IX standard English medium and Tamil medium students of the experimental group in the pre-test as well as in the post test...

\section{DISCUSSION}

The present study provides empirical data to support the learning benefits of using CHEFOVIM. The results of the preand post-tests of this study show the positive learning effects of CHEFOVIM on balancing the chemical equations by the students of the experimental group. This method promoted the students to develop a conceptual understanding of chemical representations through constructing chemical formula representations through visualization. CHEFOVIM specially improved students' ability of translating the chemical formula to empirical chemical structural formula. The results suggest that 2D (two-dimensional) chemical structural formula visualization of compounds can serve as a thinking vehicle for students to solve the problem of balancing the equations. The CHEFOVIM method has helped the students of the experimental group to visualize the chemical structural formula represented by the English alphabets (letters), write it and then balance the equation. By this method the students, especially, the concrete operational level students get the underlying principles of balancing the equations, such as law of conservation of mass, chemical formula of compounds, the addition of coefficients in the correct place (i.e. before the formula and not in between), the significance of the subscript numbers in the chemical formula etc., This method had ensured that science learning could be made interesting and easier.

No significant difference was found between boys and girls in the pre-test and the post-test for both the control and experimental groups. This supports the earlier study of (Kumar et al.2000).
The absence of significant difference between the English medium and Tamil medium students of IX standard denotes that the medium of instruction does not affect the performance of both the control and experimental group in the pre-test and the post-test irrespective of the methods taught.

\section{CONCLUSION}

In the light of the above research findings it is felt that the present study may contribute to the concrete level learners to balance the simple inorganic chemical equations with a thorough understanding. This will help them in due course to think in the abstract level. The act of forming mental image, the visualization of the expanded chemical formula of compounds has led to effective comprehension of the scientific principles involved in the chemical reactions and improved the performance of the students in balancing the chemical equations. Hence, the chemistry teachers can be given an orientation in preparing the chemical equations in CHEFOVIM format. In chemistry text books also balancing of the chemical equations can be explained through this method. Students may be trained to visualize the atoms involved in a chemical compound by writing its expanded formula by CHEFOVIM at the middle school level so that it may be easier for them to understand and balance the chemical equations at the high and higher secondary school level with hypothetico-deductive reasoning. If chemistry learning is made conceptual through proper designing and use of teaching learning situations, learning chemistry becomes very effective. It is the right time that we realize this and gear up our efforts towards providing meaningful learning experiences to our young generation through planned selection of tools and techniques.

\section{References}

Benz-Vi, R., Eylon, B., \& Silberstein, J. (1988), Theories, Principles and Laws, Education in Chemistry, May, 89.

Best, W. John. Research in Education. (4 ${ }^{\text {th }}$ Ed.) New Delhi: Prentice Hall of India Private Limited.

Buch, M. B. (Ed.), Fourth Survey of Research in Education. New Delhi: National Council of Educational Research and Training, 1983-88.

Buch, M. B. (Ed.), Fifth Survey of Research in Education. New Delhi: National council of Educational Research and Training, 1988-92.

Byrne, M. S. \& Johnstone, A. H. (1988), How to make science relevant, School Science Review, 70, 43-46.

Gabel, D. \& Sherwood, R. (1980), The effect of student manipulation of molecular models on chemistry achievement according to Piagetian level, Journal of Research in Science Teaching, 17, 75-81.

Howe \& Jhonstone A.H., (1971), Reason or Memory? The learning of formula and equations, Edinburgh, National Curriculum Development Centre Bulletin1.

Hsin-Kai, W., Joseph, S. K. \& Elliot, S. (2000), Promoting conceptual understanding of chemical representations: Students' use of a visualization tool in the classroom, Paper presented at the Annual Meeting of National Association of Research in Science Teaching, April 28 May 1, New Orleans, L.A.

Johnstone, A. H. (2006), Chemical education research in Glasgow in perspective, Chemistry Education Research and Practice, 7, 49-63. Delta Kappa Symposium on 
Education Research. Bloomington, Indiana). Niaz, M. \& Lawson, A. E. (1985), Balancing Chemical PP.97-126.

Kozma, R. B., \& Russel, J. (1997). Multimedia and understanding: $\quad$ Expert and novice responses to different representations of chemical phenomena, Journal of Research in Science Teaching, 34, 949-968.

Krajcik, J. S. (1991), Developing Students' Understanding of Chemical Concepts. In R. H. Y. S. M. Glynn, \& B. K. Britton(Ed.), The psychology of learning science, international perspective on the psychological foundations of technology-based learning environments, Hillsdale, NJ: Eribaum, PP. 117

Kumar, D. D. \& Helgeson, S. L. (2000), Effect of gender on computer-based chemistry problem solving: Early findings, Electronic Journal of Science Education, V4N4, June. Equation: The role of developmental level and mental capacity, Journal of Research in Science

\section{Websites visited for software to balance chemical equations}

Chembalancer Wizard, An on-line tutorial progam to teach balancing of chemical reactions, www.funbasedlearning.com

Brain Boggle Chembalancer, An on-line game to learn balancing of chemical reactions, www.funbasedlearning.com

Smartboard activity 'Balancing Equations' by Christi Almarode, www.explorelearning.com

\section{How to cite this article:}

Uma Rajendran and M. Sadananthan (2017) 'The Effect Of Chemical Formula Visualization Method (Chefovim) On

Balancing Simple Inorganic Chemical Equations', International Journal of Current Advanced Research, 06(05), pp. 3747-3752. DOI: http://dx.doi.org/10.24327/ijcar.2017.3752.0361 